\title{
MUDAS DE ESPÉCIES ARBÓREAS INOCULADAS COM BACTÉRIAS SOLUBILIZADORAS DE FOSFATO E FUNGOS MICORRÍZICOS ARBUSCULARES
}

\author{
Edson Luiz Souchie*, Eduardo Francia Carneiro Campello**, Orivaldo José Saggin-Júnior***, \\ Eliane M. Ribeiro da Silva**** \\ * Ciências Agrícolas, Dr., Centro Federal de Educação Tecnológica, Rio Verde, GO - esouchie@yahoo.com.br \\ ** Eng. Florestal, Dr., Embrapa Agrobiologia - campello@cnpab.embrapa.br \\ *** Eng. Agrônomo, Dr., Embrapa Agrobiologia - saggin@cnpab.embrapa.br \\ **** Eng ${ }^{\mathrm{a}}$. Florestal, Dr ${ }^{\mathrm{a}}$, Embrapa Agrobiologia - eliane@cnpab.embrapa.br \\ Recebido para publicação: 15/03/2005 - Aceito para publicação: 31/08/2005
}

\begin{abstract}
Resumo
Mudas de espécies arbóreas inoculadas com bactérias solubilizadoras de fosfato e fungos micorrízicos arbusculares. Este trabalho objetivou verificar o efeito da inoculação de bactérias solubilizadoras de fosfato na formação de mudas de espécies arbóreas em viveiro. Mudas de Acacia holosericea, Mimosa caesalpiniifolia, Anadenanthera macrocarpa, Enterolobium contortisiliquum, Schinus terebinthifolius e Eucalyptus grandis foram formadas em viveiro durante 11 meses. As espécies fixadoras de $\mathrm{N}_{2}$ foram inoculadas com rizóbio e fungos micorrízicos arbusculares (FMAs) enquanto que as não fixadoras apenas com FMAs. Além disso, metade das mudas foi inoculada com bactérias solubilizadoras de fosfato. A população inoculada de bactérias solubilizadoras decresceu durante a formação de mudas. Por outro lado, a inoculação dessas bactérias foi benéfica para formação de mudas de Anadenanthera macrocarpa, Mimosa caesalpiniifolia e Acacia holosericea. inibindo, entretanto, o desenvolvimento de Enterolobium contortisiliquum.

Palavras-chave: Sinergismo; fósforo; viveiro; fixação de N2; leguminosas.
\end{abstract}

\begin{abstract}
Tree species seedlings inoculated with p-solubilizing bacteria and arbuscular mycorrhizal fungi. This study aimed to verify the inoculation of P-solubilizing bacteria effect on the growth of tree species seedlings cultivated under nursery conditions. Acacia holosericea, Mimosa caesalpiniifolia, Anadenanthera macrocarpa, Enterolobium contortisiliquum, Schinus terebinthifolius and Eucalyptus grandis were grown in nursery during 11 months. $\mathrm{N}_{2}$-fixing tree species were inoculated with rhizobia and arbuscular mycorrhizal fungi (AMF) while Non- $\mathrm{N}_{2}$-fixing tree species were inoculated only with AMF. Otherwise, half of the plants were inoculated with P-solubilizing bacteria. Population of $P$-solubilizing bacteria inoculated decreased during plant growth. On the other hand, these bacteria stimulated the growth of Anadenanthera macrocarpa, Mimosa caesalpiniifolia and Acacia holosericea in spite of inhibiting growth of Enterolobium contortisiliquum.

Keywords: Synergism; phosphorus; nursery; N2-fixing; leguminous.
\end{abstract}

\section{INTRODUÇÃO}

A inoculação de microrganismos benéficos em plantas tem sido empregada para melhorar seu desenvolvimento (Caravaca et al., 2002) e aumentar a tolerância a doenças (Green et al., 1999), além de favorecer seu estabelecimento frente a condições adversas, como salinidade (Rao e Tarafdar, 1998; Giri e Mukerji, 2004) e estresse hídrico (Ruiz-Lozano et al., 2001). Dentre os grupos de microrganismos com comprovado potencial de benefício para as plantas, tem-se as bactérias do gênero rizóbio (Rao e Tak, 2001; Bala et al., 2003), bactérias solubilizadoras de fosfato (Gull et al., 2004) e fungos micorrízicos arbusculares (FMAs) (Rao e Tak, 2002). Esses microrganismos podem beneficiar o desenvolvimento de mudas em viveiros, maximizando a capacidade de estabelecimento dessas mudas em campo. As bactérias 
do gênero rizóbio são capazes de formar simbiose com espécies de leguminosas arbóreas, possibilitando a fixação do $\mathrm{N}_{2}$ atmosférico, garantindo o suprimento desse elemento à planta. Franco e Faria (1997) relatam que a presença de fungos micorrízicos arbusculares (FMAs) aumenta a capacidade de espécies leguminosas arbóreas fixadoras de $\mathrm{N}_{2}$ absorverem nutrientes, principalmente $\mathrm{P}$ e água do solo.

Além de rizóbio e FMAs, a aplicação de inoculante de solubilizadores de fosfato ou o manejo de suas populações no solo constituem alternativas para a melhoria do suprimento de fósforo para as plantas (Silva Filho e Vidor, 2000). Bactérias solubilizadoras de fosfato podem atuar como "mycorrhiza helper bacteria", melhorando o estabelecimento dos fungos micorrízicos (Toro et al., 1997), além de solubilizarem fosfatos através da liberação de ácidos orgânicos, produtos de seu metabolismo, favorecendo o desenvolvimento vegetal (Gull et al., 2004). Além disso, as bactérias solubilizadoras de fosfato podem atuar sinergisticamente com rizóbios, favorecendo a nodulação, já que disponibilizam $P$ para a planta. Tendo em vista que a fixação biológica de $\mathrm{N}_{2}$ é um processo exigente em $\mathrm{P}$, justificam-se estudos visando maximizar seu fornecimento de forma econômica.

Dessa forma, é interessante conhecer as inter-relações entre esses microrganismos, buscando seu uso na forma de inoculantes, em prol da nutrição e do melhor estabelecimento de espécies arbóreas em áreas degradadas ou de difícil estabelecimento, como nas pastagens.

Nesse sentido, o presente trabalho objetivou verificar o efeito da inoculação de bactérias solubilizadoras de fosfato na formação de mudas de espécies arbóreas co-inoculadas com FMAs e, quando leguminosas, com rizóbios.

\section{MATERIAL E MÉTODOS}

No viveiro da Embrapa Agrobiologia, foram produzidas mudas das seguintes espécies arbóreas, fixadoras de $\mathrm{N}_{2}$ : timbaúva (Enterolobium contortisiliquum), angico (Anadenanthera macrocarpa), holoserícea (Acacia holosericea) e sabiá (Mimosa caesalpiniifolia); e não-fixadoras: aroeira (Schinus terebinthifolius), ipê-amarelo (Tabebuia chrysotricha) e eucalipto (Eucalyptus grandis). Antes da semeadura, foi feita a quebra de dormência das sementes de A. holosericea, M. caesalpiniifolia e $E$. contortisiliquum conforme Fowler e Martins (2001). As sementes foram pré-germinadas em substrato composto de areia e vermiculita 2:1 (v/v). Em seguida, as plântulas foram transplantadas para bandejas de isopor de 72 células, contendo por célula $100 \mathrm{~cm}^{3}$ de um substrato composto de areia, argila e composto orgânico na proporção 4:3:1 (v/v). Foram produzidas 200 mudas de cada espécie, sendo cada muda inoculada no orifício de transplante com 3,0 g de inóculo de FMAs, que continha 21 e 5 esporos g ${ }^{-1}$ de Gigaspora margarita e Glomus clarum, respectivamente, além de hifas desses fungos e raízes de Brachiaria decumbens micorrizadas. As leguminosas foram inoculadas com $1 \mathrm{~mL}$ de meio líquido 79 , contendo 4,2 × $10^{7}$ células de rizóbio, sendo utilizadas as estirpes BR 3407 e BR 3446 para $M$. caesalpiniifolia, BR 4407 e BR 6205 para E. contortisiliquum, BR 9001 e BR 9004 para A. macrocarpa e BR 5608 e BR 4406 para A. holosericea. Essas foram crescidas separadamente e misturadas no momento da inoculação. Como tratamentos de inoculação de bactérias solubilizadoras de fosfato (BSF), metade das mudas foram inoculadas com uma mistura de três isolados, denominados BSF 6, BSF 7 e BSF 14, obtidos do rizoplano mais rizosfera de $M$. caesalpiniifolia cultivada em um argissolo procedente da região da Floresta Atlântica do município de Paraty (RJ). Para a inoculação, pipetou-se no orifício de transplante 1 $\mathrm{mL}$ de meio líquido GL (Sylvester-Bradley et al., 1982), contendo $1,1 \times 10^{8}$ Unidades Formadoras de Colônias (UFC).

$\mathrm{O}$ crescimento das mudas foi avaliado mensalmente, medindo-se a altura e diâmetro de 16 plantas de cada espécie tomadas aleatoriamente, sendo oito inoculadas com BSF e oito não. Após 11 meses em viveiro, as mudas foram consideradas formadas e determinou-se matéria fresca e seca de parte aérea, raízes e nódulos, número de nódulos e densidade de BSF em 20 plantas de cada tratamento, também escolhidas aleatoriamente.

Como as mudas foram amostradas aleatoriamente, o delineamento experimental foi inteiramente casualizado em esquema fatorial $6 \times 2$ (6 espécies arbóreas x 2 tratamentos de BSF), com 8 repetições nas avaliações mensais de crescimento e 20 repetições na avaliação final.

Os dados foram submetidos à análise de variância e as médias dos tratamentos de BSF comparadas pelo teste F (5\%), teste t $(1,5$ e $10 \%)$ e as das espécies arbóreas por Scott-Knott (5\%), utilizando o programa estatístico Sisvar (Furtado, 1998). 


\section{RESULTADOS E DISCUSSÃO}

Não foi verificado efeito da inoculação com BSF na altura e diâmetro do caule de nenhuma das espécies arbóreas, ao longo dos 11 meses de cultivo em viveiro (dados não apresentados). Da mesma forma, após 11 meses de cultivo, não foi verificado efeito dessa inoculação com BSF nessas variáveis (Tabela 1). Também observou-se pouco efeito significativo no aumento da população de BSF no substrato (Tabela 2), sendo significativamente maior apenas a população dessas bactérias em $S$. terebinthifolius inoculado com BSF. Entretanto, observando-se mais cautelosamente os dados da Tabela 2 , verifica-se que, apesar do pouco efeito significativo, houve propensão de a população de bactérias solubilizadoras ser maior no tratamento inoculado com as BSF, particularmente em A. macrocarpa e $M$. caesalpiniifolia, onde as populações de bactérias solubilizadoras foram muito baixas no tratamento não inoculado com BSF.

Tabela 1. Altura e diâmetro das mudas das espécies arbóreas inoculadas ou não com bactérias solubilizadoras de fosfato (BSF), após 11 meses de cultivo em viveiro.

Table 1. Height and diameter of tree species inoculated $(+)$ or not (-) with P-solubilizing bacteria (PSF), after 11 months of growth in nursery.

\begin{tabular}{|c|c|c|c|}
\hline Espécies arbóreas & BSF & Altura (cm) & Diâmetro (mm) \\
\hline \multirow[b]{2}{*}{ A. macrocarpa } & inoculadas & $19 \mathrm{~ns}^{1}$ & $5,2 \mathrm{~ns}$ \\
\hline & não-inoculadas & 16 & 6,4 \\
\hline \multirow{2}{*}{ M. caesalpiniifolia } & inoculadas & $20 \mathrm{~ns}$ & $4,5 \mathrm{~ns}$ \\
\hline & não-inoculadas & 18 & 3,9 \\
\hline \multirow{2}{*}{ A. holosericea } & inoculadas & $25 \mathrm{~ns}$ & $4,2 \mathrm{~ns}$ \\
\hline & não-inoculadas & 24 & 3,7 \\
\hline \multirow{2}{*}{ E. contortisiliquum } & inoculadas & $23 \mathrm{~ns}$ & $5,6 \mathrm{~ns}$ \\
\hline & não-inoculadas & 28 & 6,5 \\
\hline \multirow{2}{*}{ S. terebinthifolius } & inoculadas & $13 \mathrm{~ns}$ & $4,2 \mathrm{~ns}$ \\
\hline & não-inoculadas & 14 & 3,9 \\
\hline \multirow{2}{*}{ E. grandis } & inoculadas & $32 \mathrm{~ns}$ & $3,0 \mathrm{~ns}$ \\
\hline & não-inoculadas & 29 & 2,7 \\
\hline
\end{tabular}

Tabela 2. Densidade populacional de bactérias e fungos solubilizadores e não solubilizadores de fosfato em espécies arbóreas inoculadas (Inoc) ou não (Ni) com três isolados de BSF, após 150 dias de cultivo em viveiro.

Table 2. P-solubilizing and P-non solubilizing bacteria and fungi in tree species inoculated (Inoc) or not (Ni) with three P-solubilizing bacteria isolates, after 150 days of growth in nursery.

\begin{tabular}{|c|c|c|c|c|c|c|c|c|}
\hline \multirow{3}{*}{ Espécie arbórea } & \multicolumn{4}{|c|}{ Bactérias } & \multicolumn{4}{|c|}{ Fungos } \\
\hline & \multicolumn{2}{|c|}{ Solubilizadoras } & \multicolumn{2}{|c|}{ Não-solubiliz. } & \multicolumn{2}{|c|}{ Solubilizadores } & \multicolumn{2}{|c|}{ Não-solubiliz. } \\
\hline & Inoc & $\mathbf{N i}$ & Inoc & $\mathbf{N i}$ & Inoc & $\mathbf{N i}$ & Inoc & $\mathbf{N i}$ \\
\hline & -------- & --- & $---10^{3}$ & g solo & $\mathrm{eco}^{-1}$ & & - & \\
\hline A. macrocarpa & $1,9 b$ & $0 \mathrm{a}$ & $94,8 a^{*}$ & $37,5 \mathrm{a}$ & $0,3 \mathrm{a}$ & $1,2 b$ & $2,8 \mathrm{~b}$ & $2,5 \mathrm{a}$ \\
\hline M. caesalpiniifolia & $1,5 b$ & $0,4 \mathrm{a}$ & $45,7 b$ & $42,9 a$ & $0,1 \mathrm{a}$ & $0,1 b$ & $6,3 a^{*}$ & $2,5 \mathrm{a}$ \\
\hline A. holosericea & $2,4 \mathrm{~b}$ & $1,7 \mathrm{a}$ & $34,1 b$ & $36,3 a$ & $0 \mathrm{a}$ & $0,1 b$ & $1,2 \mathrm{~b}$ & $2,7 \mathrm{a}$ \\
\hline E. contortisiliquum & $0,3 b$ & $0,3 \mathrm{a}$ & $36,1 b$ & $49,5 \mathrm{a}$ & $0,1 \mathrm{a}$ & $1,6 \mathrm{a}$ & $4,7^{\mathrm{a}}$ & $2,6 a$ \\
\hline S. terebinthifolius & $11,0 \mathrm{a}^{*}$ & $1,7 \mathrm{a}$ & $55,6 \mathrm{~b}$ & $28,6 a$ & $0 \mathrm{a}$ & $0 \mathrm{~b}$ & $0,9 b$ & $0,8 \mathrm{a}$ \\
\hline E. grandis & $0,6 \mathrm{~b}$ & $0,5 \mathrm{a}$ & $38,5 b$ & $53,7 \mathrm{a}$ & $0,1 \mathrm{a}$ & $0,4 \mathrm{~b}$ & $4,9^{\mathrm{a}}$ & $7,0 \mathrm{a}$ \\
\hline
\end{tabular}

Letras iguais nas colunas indicam ausência de diferença entre as espécies arbóreas dentro de cada tratamento de inoculação de BSF pelo teste Scott Knott 5\%. * indica superioridade do tratamento de inoculação de BSF dentro de cada espécie, pelo teste t 5\%.

Em relação às bactérias não-solubilizadoras, fungos solubilizadores e não-solubilizadores, o efeito da inoculação de BSF também foi pequeno, sendo apenas significativo para A. macrocarpa e $M$. caesalpiniifolia, em que a inoculação de BSF aumentou bactérias e fungos não-solubilizadores, respectivamente. A maior densidade de bactérias solubilizadoras foi observada para S. terebinthifolius 
inoculado, e a de não-solubilizadoras foi observada em A. macrocarpa. Para fungos solubilizadores, foi observada uma maior densidade em E. contortisilquum não inoculada, e a de fungos não-solubilizadores nas plantas de E. grandis, M. caesalpiniifolia e E. contortisiliquum inoculadas com BSF (Tabela 2).

Com relação à produção de matéria seca de parte aérea, raízes e nódulos das mudas de $A$. macrocarpa e $M$. caesalpiniifolia, houve efeito benéfico significativo da inoculação das BSF, não aumentando apenas o número de nódulos (Tabela 3). Em A. holosericea, verificou-se efeito benéfico menor onde a inoculação de BSF aumentou apenas a matéria fresca de parte aérea e nódulos e número de nódulos. Ao contrário, E. contortisiliquum apresentou maior crescimento no tratamento não inoculado com BSF, sendo isso significativo para a matéria fresca de parte aérea, matéria fresca e seca de raízes. Nas demais espécies arbóreas, não foi verificado efeito da inoculação de BSF (Tabela 3).

Tabela 3. Matéria fresca e seca de parte aérea, raízes, nódulos e número de nódulos de mudas de espécies arbóreas inoculadas (Inoc) ou não (Ni) com BSF, após 11 meses de cultivo em viveiro (média de 10 mudas).

Table 3. Fresh and dry weight of shoot, roots, nodules and number of nodules of tree species inoculated (Inoc) or not $(\mathrm{Ni})$ with P-solubilizing bacteria, after 11 months of growth in nursery (average of 10 plants).

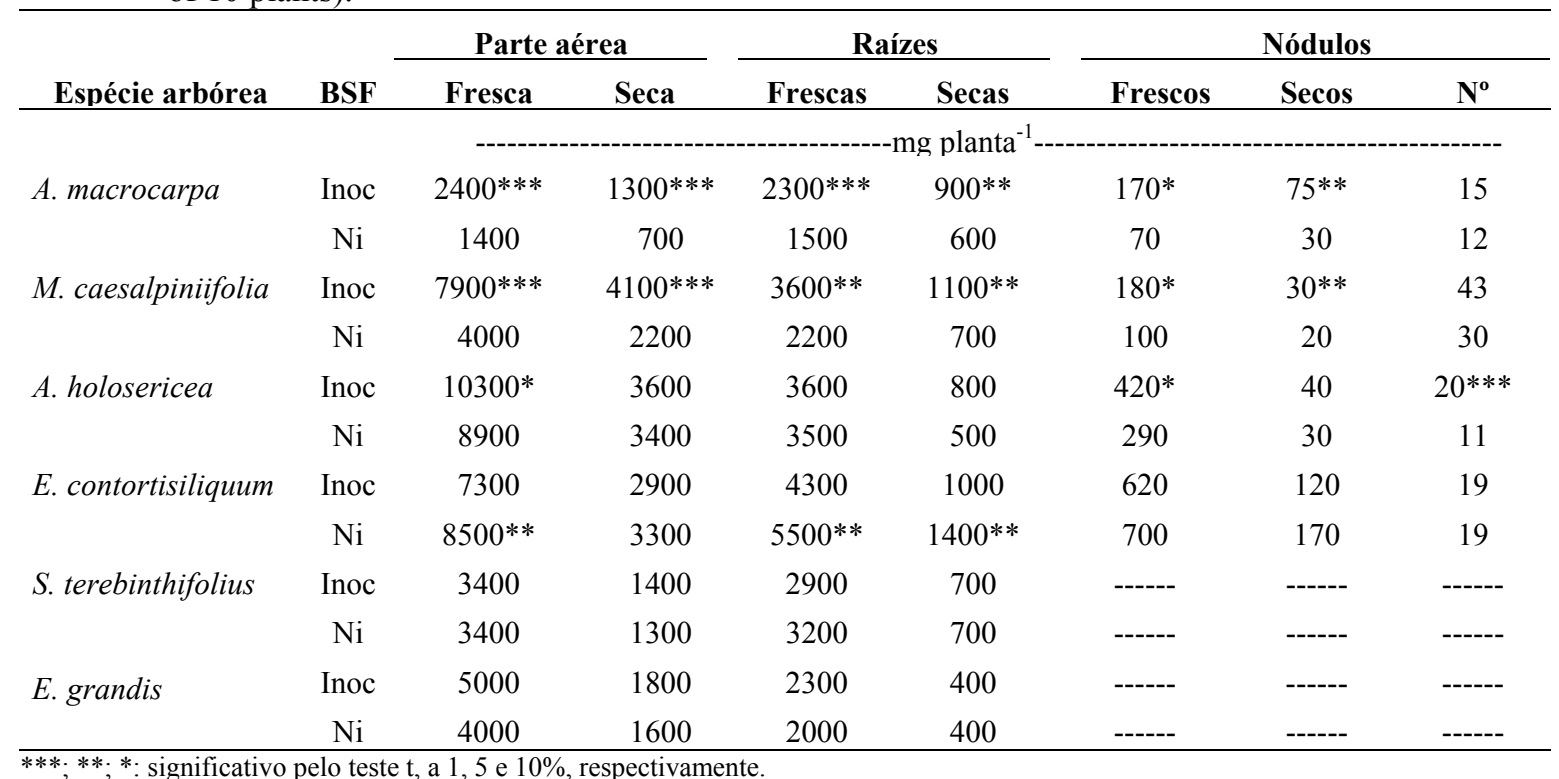

Houve benefício da inoculação de BSF no crescimento e nodulação de mudas de $A$. macrocarpa, M. caesalpiniifolia e $A$. holosericea, que são fixadoras de $\mathrm{N}_{2}$. Embora a avaliação da capacidade de solubilização de fosfato das BSF inoculadas não tenha sido o objetivo deste trabalho, as bactérias provavelmente podem ter melhorado a nutrição dessas plantas durante a formação das mudas. Fica claro, entretanto, que houve algum grau de sinergismo das BSF junto aos rizóbios, promovendo o crescimento e nodulação das fixadoras de $\mathrm{N}_{2}$. Por outro lado, o efeito das BSF não é unicamente nutricional, pois ele pode ser negativo, como no caso de E. contortisiliquum, que também é fixadora. Portanto, existem combinações entre BSF e plantas que não são favoráveis, e os fatores que explicam esses efeitos precisam ser evidenciados com outros estudos. É provável que houve algum tipo de incompatibilidade entre as BSF inoculadas e E. contortisiliquum ou entre os próprios microrganismos na sua rizosfera. As três BSF utilizadas neste estudo foram isoladas do rizoplano mais rizosfera de $M$. caesalpiniifolia, o que pode favorecer seu estabelecimento quando inoculadas nessa mesma espécie arbórea. Founoune et al. (2002) relatam incremento de biomassa de parte aérea e raízes de $A$. holosericea com a inoculação de bactérias solubilizadoras consideradas estimuladoras de micorrizas ("mycorrhiza helper bacteria"). Por outro lado, há trabalhos demonstrando certa incompatibilidade entre FMAs e Rhizobium spp (Santiago et al., 2002; Khaled et al. 2003; Xavier e Germida, 2003). As espécies não-fixadoras (S. terebinthifolius e E. grandis) 
mostraram-se indiferentes à inoculação de BSF quanto ao crescimento. Pelo fato de não fixarem, podem sofrer menos influência das relações microbianas rizosféricas ou apresentar menor demanda interna de P, respondendo menos a essas bactérias.

$\mathrm{O}$ fato de os efeitos da inoculação de BSF não terem sido detectados na altura e diâmetro do caule das mudas possivelmente se deve a essas variáveis serem muito afetadas pela competição por luminosidade quando cultivadas em bandejas de polipropileno, ocorrendo freqüentemente algum grau de estiolamento. Além disso, a baixa população de bactérias solubilizadoras encontradas no substrato sugere que os isolados de BSF inoculados entram em equilíbrio populacional com a microbiota restante em um período de tempo inferior ao da formação das mudas. Isso também pode ter contribuído para a inexistência do efeito de inoculação das BSF em algumas das espécies arbóreas, como E. grandis e $S$. terebinthifolius. Gyaneshwar et al. (2002) relatam que, embora a solubilização de compostos de P por microrganismos seja muito comum sob condições de laboratório, em nível de campo os resultados têm sido altamente variáveis. Isso tem limitado o uso desses microrganismos em larga escala na agricultura. Richardson (2001) sugere que, apesar dos solubilizadores de fosfato apresentarem potencial de uso como inoculantes, sua ampla aplicação permanece limitada devido à falta de conhecimento sobre ecologia microbiana e dinâmica das populações no solo. Dessa forma, futuros estudos são necessários visando evidenciar as inter-relações entre esses microrganismos e plantas para viabilizar seu uso na forma de inoculantes.

\section{CONCLUSÕES}

- A inoculação da BSF 6, BSF 7 e BSF 14 foi benéfica para formação de mudas de $A$. macrocarpa, $M$. caesalpiniifolia e A. holosericea, entretanto, inibiram o desenvolvimento de mudas de E. contortisiliquum.

- Os isolados de BSF inoculados favoreceram a nodulação de A. macrocarpa, $M$. caesalpiniifolia e A. holosericea.

\section{AGRADECIMENTOS}

Ao PRODETAB, pelo financiamento deste projeto, e à Embrapa Agrobiologia, pela infraestrutura.

\section{REFERÊNCIAS}

BALA, A.; MURPHY, P. J.; OSUNDE, A. O.; GILLER, K. E. Nodulation of tree legumes and the ecology of their native rhizobial populations in tropical soils. Applied Soil Ecology, Columbus, v.22, n.3, p.211-223, 2003.

KHALED, L. B.; GOMEZ, A. M.; QUARRAQI, E. M.; OIHABI, A. Physiological and biochemical responses to salt stress of mycorrhized and/or nodulated clover seedlings (Trifolium alexandrinum L.). Agronomie, Paris, v.23, n.7, p.571-580, 2003.

CARAVACA, F.; BAREA, J. M.; FIGUEROA, D.; ROLDAN, A. Assessing the effectiveness of mycorrhizal inoculation and soil compost addition for enhancing reafforestation with Olea europaea susbs sylvestris through changes in soil biological and physical parameters. Applied Soil Ecology, Columbus, v.20, n.2, p.107-118, 2002.

FOUNOUNE, H.; DUPONNOIS, D. B. A.; BRANGET, I.; LORQUIN, J.; NEYRA, M.; CHOTTE, J. L. Mycorrhiza helper bacteria stimulate ectomycorrhizal symbiosis of Acacia holosericea with Pisolithus alba. New Phytologyst, Cambridge, v.153, n.1, p.81-89, 2002.

FOWLER, J. A. P.; MARTINS, E. G. Manejo de sementes de espécies florestais. Colombo: Embrapa Florestas, 2001. 76p. (Documentos, 58).

FRANCO, A. A.; FARIA, S. M. de. The contribution of nitrogen fixing tree legumes to land reclamation and sustainability in the tropics. Soil Biology and Biochemistry, Orlando, v.29, n.5-6, p.897-904, 1997. 
FURTADO, D. F. Programa Sisvar.exe: sistema de análise de variância, UFLA, Lavras, 1998.

GIRI, B.; MUKERJI, K. Mycorrhizal inoculant alleviates salt stress in Sesbania aegyptiaca and Sesbania grandiflora under field conditions: evidence for reduced sodium and improved magnesium uptake. Mycorrhiza, New York, v.14, n.5, p.307-312, 2004.

GREEN, H.; LARSEN, J.; OLSSON, P. A.; JENSEN, D. F.; JACOBSEN, I. Suppression of the biocontrol agent Trichoderma harzianum by mycelium of the arbuscular mycorrhizal fungus Glomus intraradices in toot-free soil. Applied Environmental Microbiology, Washington , v.65, n.4, p.14281434, 1999.

GULL, M.; HAFEEZ, F. Y.; SALEEM, M.; MALIK, K. A. Phosphorus uptake and growth promotion of chickpea by co-inoculation of mineral phosphate solubilising bacteria and a mixed rhizobial culture. Australian Journal of Experimental Agriculture, Collingwood, v.44, n.6, p.623-628, 2004.

GYANESHWAR. P.; KUMAR, G. N.; PAREKH, L. J.; POOLE, P. S. Role of soil microorganisms in improving P nutrition of plants. Plant and Soil, Dordrecht, v.45, n.1, p.83-93, 2002.

RAO, A. V.; TARAFDAR, J. C. Significance of microorganisms in afforestation programmes in arid zone. Annals of Arid Zone, Jodhpur, v.37, n.4, p.337-346, 1998.

RAO, A.V.; TAK, R. Effect of rhizobial inoculation on Albizia lebbeck and its rhizosphere activity in mine spoils. Arid Land Research and Management, Logan, v. 15, n. 2, p. 157-162, 2001.

RAO, A. V.; TAK, R. Growth of different tree species and their nutrient uptake in limestone mine spoil as influenced by arbuscular mycorrhizal (AM) - fungi in Indian Arid zone. Journal of Arid Environments, Buenos Aires, v.51, n.1, p.113-119, 2002.

RICHARDSON, A. E. Prospects for using soil microorganisms to improve the acquisition of phosphorus by plants. Australian Journal of Plant Physiology, Collingwood, v.28, n.9, p.897-906, 2001.

RUIZ-LOZANO, J. M.; COLLADOS, C.; BAREA, J. M.; AZCÓN, R. Arbuscular mycorrhizal symbiosis can alleviate drought-induced nodule senescence in soybean plants. New Phytologyst, Cambridge, v.151, n.2, p.493-502, 2001.

SANTIAGO, G. M.; GARCIA, Q.; SCOTTI, M. R. Effect of post-planting inoculation with Bradyrhizobium sp and mycorrhizal fungi on the growth of Brazilian rosewood, Dalbergia nigra Allem. ex Benth., in two tropical soils. New Forests, Dordrecht, v.24, n.1, p.15-25, 2002.

SILVA FILHO, G. N.; VIDOR, C. Solubilização de fosfatos por microrganismos na presença de fontes de carbono. Revista Brasileira de Ciência do Solo, Viçosa, MG, v.24, n.2, p.311-319, 2000.

SYlVESTER-BRADLEY, R.; ASKAWA, N.; LATORRACA, S.; MAGAlHÃES, F. M. M.; OLIVEIRA, L. A.; PEREIRA, R. M. Levantamento quantitativo de microrganismos solubilizadores de fosfato na rizosfera de gramíneas e leguminosas forrageiras na Amazônia. Acta Amazonica, Manaus, v.12, n.1, p.12-22, 1982.

TORO, M.; AZCÓN, R.; BAREA, J. M. Improvement of arbuscular mycorrhiza development by inoculation of soil with phosphate-solubilizing rhizobacteria to improve rock phosphate bioavailability $\left(\mathrm{P}_{32}\right)$ and nutrient cycling. Applied and Environmental Microbiology, Washington , v.63, n.11, p.44084412, 1997.

XAVIER, L. J. C.; GERMIDA, J. J. Selective interactions between arbuscular mycorrhizal fungi and Rhizobium leguminosarum bv. Viceae enhance pea yield and nutrition. Biology and Fertility of Soils, New York, v.37, p.261-267, 2003. 